Discussion Paper No. 978

\title{
EXCLUSIVE CONTRACTS \\ AND \\ BARGAINING POWER
}

\author{
Hiroshi Kitamura \\ Noriaki Matsushima \\ Misato Sato
}

September 2016

The Institute of Social and Economic Research Osaka University

6-1 Mihogaoka, Ibaraki, Osaka 567-0047, Japan 


\title{
Exclusive Contracts and Bargaining Power*
}

\author{
Hiroshi Kitamura $^{\dagger} \quad$ Noriaki Matsushima ${ }^{\ddagger} \quad$ Misato Sato ${ }^{\S}$
}

September 8, 2016

\begin{abstract}
This study constructs a simplest model to examine anticompetitive exclusive contracts that prevent a downstream buyer from buying input from a new upstream supplier. Incorporating Nash bargaining into the standard one-buyer-onesupplier framework in the Chicago School critique, we show a possibility that an inefficient incumbent supplier can deter a socially efficient entry through exclusive contracts.
\end{abstract}

JEL classifications code: L12, L41, L42, C72.

Keywords: Antitrust policy; Entry deterrence; Exclusive contracts; Nash bargaining.

*This paper is a divided part of Kitamura et al. (2016b) "Exclusive Contracts with Complementary Input." We extract Section 4.2 in Kitamura et al. (2016b) and revise it. We gratefully acknowledge financial support from JSPS KAKENHI Grant Numbers JP15H03349, JP15H05728, and JP15K17060, and the program of the Joint Usage/Research Center for 'Behavioral Economics' at ISER, Osaka University. The usual disclaimer applies.

${ }^{\dagger}$ Faculty of Economics, Kyoto Sangyo University, Motoyama, Kamigamo, Kita-Ku, Kyoto, Kyoto 603-8555, Japan. Email: hiroshikitamura@cc.kyoto-su.ac.jp

$\ddagger$ Institute of Social and Economic Research, Osaka University, 6-1 Mihogaoka, Ibaraki, Osaka 5670047, Japan. Email: nmatsush@iser.osaka-u.ac.jp

$\S$ Department of Economics, The George Washington University, 2115 G street, NW Monroe Hall 340 Washington DC 20052, USA. Email: smisato@gwmail.gwu.edu 


\section{Introduction}

Among the issues of vertical restraints (e.g., exclusive contracts, loyalty rebates, slotting fees, resale price maintenance, quantity fixing, and tie-ins), ${ }^{1}$ exclusive contracts have long been controversial, especially since the Chicago School critique (Posner, 1976; Bork, 1978), which argue that the rational buyer does not sign such a contract to deter a more efficient entrant. ${ }^{2}$

By incorporating additional players into the baseline setting in the Chicago School, many papers examine possibilities of signing anticompetitive exclusive contracts (e.g., scale economies (Rasmusen, Ramseyer, and Wiley, 1991; Segal and Whinston, 2000) and competition between the buyers (Simpson and Wickelgren, 2007; Abito and Wright, 2008)). ${ }^{3}$ By contrast, we show a possibility that an anticompetitive exclusive contract attains under a one-buyer-one-supplier framework with one potential supplier. The key factor of our model is incorporating Nash bargaining into the baseline setting in the Chicago School. ${ }^{4}$ Under the extended setting, upstream competition through entry does not generate enough buyer profits if the buyer has weaker bargaining power. Anticipating the outcome, the buyer agrees with an exclusive contract offered by the incumbent. This contrasts with the Chicago School's setting in which entry generates fierce upstream Bertrand competition that induces the buyer to reject an exclusive offer.

Fumagalli et al. (2012) is also the study which shows a possibility that an anticompetitive exclusive contract attains under a one-buyer-one-supplier framework with one potential supplier. The novelty of their model is incorporating incumbent's investments

${ }^{1}$ Excellent surveys of vertical restraints are available in Rey and Tirole (2007) and Rey and Vergé (2008).

2 Motta (2004) and Whinston (2006) explain discussions on the impact of the Chicago School argument on antitrust policies.

3 Aghion and Bolton (1987) is the pioneering work that shows a possibility that an anticompetitive contract attains.

${ }^{4}$ In the context of vertical relations, Nash bargaining has been used in many papers (e.g., recently, Aghadadashli et al., 2016). 
which improve the value of ex-post trade into the traditional one-buyer-one-supplier model. ${ }^{5}$ The differences between Fumagalli et al. (2012) and ours are as follows. We do not take into account incumbent's investments. We instead change the bargaining process, which generates a crucial difference when two suppliers are active. Fumagalli et al. (2012) assume Nash bargaining with random proposers in which the homogeneous Bertrand competition occurs if two suppliers make price offers. In their setting, exclusion never occurs in the absence of investments because the buyer can earn large profit when entry occurs. By contrast, we assume that the buyer sequentially negotiates with two suppliers. More concretely, it first negotiates with an efficient entrant supplier. It then negotiates with an inefficient incumbent supplier if the previous negotiation breaks down. This implies that the incumbent supplier becomes an outside option of the buyer if the entrant exists. Under the modified framework, the competition between suppliers for the case of socially efficient entry is less intense than under homogeneous Bertrand competition, which leaves room for exclusion even in the absence of investments.

The rest of this paper proceeds as follows. Section 2 introduces the model. Section 3 then presents the main results.

\section{Model}

This section develops the basic model. The upstream market consists of an upstream incumbent $U_{I}$ with constant marginal cost $c_{I}>0$ and an upstream entrant $U_{E}$ with constant marginal cost $c_{E} \in\left[0, c_{I}\right)$. Each of them is able to supply input to a downstream buyer $D$ which is able to produce one unit of final product by using one unit of input. The downstream demand is given by $Q(p)$, which is continuous and $Q^{\prime}(p)<0$. We assume that $(p-z) Q(p)$ is strictly and globally concave in $p ; 2 Q^{\prime}(p)+(p-z) Q^{\prime \prime}(p)<0$.

The model contains four stages. In Stage $1, U_{I}$ offers an exclusive contract to $D$. This contract involves some fixed compensation $x \geq 0$. D decides whether to accept

\footnotetext{
${ }^{5}$ Kitamura et al. (2016a) shows a possibility that an exclusive contract attains under a one-buyerone-supplier framework with one potential buyer.
} 
this offer.

In Stage 2, after observing $D$ 's decision, $U_{E}$ decides whether to enter the upstream market. We assume that the fixed cost of entry $f(>0)$ is sufficiently small, such that if $U_{E}$ is active, it could earn positive profits.

In Stage 3, existing firms negotiate and make contracts for two-part tariffs. We assume that the outcome of every negotiation is given by Nash bargaining solution and that the bargaining power of $D$ over each upstream firm $\beta \in(0,1)$. Depending on $D$ 's decision in Stage 1, two scenarios can emerge. If $D$ accepts the offer, $D$ negotiates with $U_{I}$, and makes contracts for the two-part tariffs consisting of a linear wholesale price and an upfront fixed fee $\left(w_{I}^{a}, F_{I}^{a}\right)$ if they reach an agreement. If the negotiation between them breaks down, they gain nothing. By contrast, if $D$ rejects the offer, the two suppliers are active. In this case, $D$ first negotiates with $U_{E}$, and makes contracts for the two-part tariffs $\left(w_{E}^{r}, F_{E}^{r}\right)$, if they reach an agreement. ${ }^{6}$ If the negotiation between them breaks down, $U_{E}$ exits. Then, $D$ negotiates with $U_{I}$, and makes contracts for the two-part tariffs $\left(w_{I}^{r}, F_{I}^{r}\right)$ if they reach an agreement. If the negotiation between them breaks down, they gain nothing.

In Stage 4, D determines its price if a negotiation is reached with one of the upstream firms.

Given the equilibrium outcomes in the subgame following Stage 1, we derive the essential conditions for an exclusive contract. Let $\pi_{i}^{j}$ be the profit of $i\left(i=D, U_{I}\right)$ under state $j$ ( $j=a, r$, where $a$ and $r$ indicate 'Accept' and 'Reject'). For an exclusion equilibrium, the equilibrium transfer $x^{*}$ must satisfy the following two conditions.

First, it must satisfy the individual rationality for $U_{I}$; that is, $U_{I}$ must earn higher operating profits under exclusive dealing, such that

$$
\pi_{U_{I}}^{a}-x^{*} \geq \pi_{U_{I}}^{r} \text { or } \quad x^{*} \leq \pi_{U_{I}}^{a}-\pi_{U_{I}}^{r}
$$

Second, it must satisfy the individual rationality for $D$; that is, the compensation

\footnotetext{
${ }^{6}$ It is not optimal for $D$ to bargain first with $U_{I}$.
} 
amount $x$ must induce $D$ to accept the exclusive offer, such that

$$
x^{*}+\pi_{D}^{a} \geq \pi_{D}^{r} \text { or } \quad x^{*} \geq \pi_{D}^{r}-\pi_{D}^{a}
$$

From the above conditions, it is easy to see that an exclusion equilibrium exists if and only if inequalities (1) and (2) hold simultaneously. That is, an exclusion equilibrium exists, if the highest value of $x^{*}$ in inequality (1) is larger than or equal to the lowest value of $x^{*}$ in inequality (2). This is equivalent to the following condition:

$$
\pi_{U_{I}}^{a}+\pi_{D}^{a} \geq \pi_{D}^{r}+\pi_{U_{I}}^{r}
$$

Condition (3) implies that for the existence of anticompetitive exclusive contracts, we must examine whether exclusive agreements increase the joint profits of $D$ and $U_{I}$.

\section{Result}

We solve the game by using backward induction. In Stage 4, given the agreed wholesale price $w, D$ sets $p(w)$ to maximize its profit, such that

$$
p(w) \equiv \underset{p}{\arg \max }(p-w) Q(p)
$$

For notational convenience, we define the gross downstream profit given $w$ as $\Pi(w) \equiv$ $(p(w)-w) Q(p(w))$. The rest of this section is organized as follows. We first consider the case in which $D$ accepts the exclusive offer in 3.1. We then explore the case in which $D$ rejects the exclusive offer in 3.2. Finally, we examine the existence of anticompetitive exclusive contracts in 3.3 .

\subsection{D accepts the exclusive offer}

The bargaining problem between $D$ and $U_{I}$ in Stage 3 is given as

$\left(w_{I}^{a}, F_{I}^{a}\right)=\arg \max _{w, F} \beta \log [(p(w)-w) Q(p(w))-F]+(1-\beta) \log \left[\left(w-c_{I}\right) Q(p(w))+F\right]$ 
Assuming $\left(w-c_{I}\right) Q(p(w))$ is strictly and globally concave in $w$, the maximization problem leads to the following two equations:

$$
\begin{aligned}
& -\frac{\beta Q\left(p\left(w_{I}^{a}\right)\right)}{\Pi\left(w_{I}^{a}\right)-F_{I}^{a}}+\frac{(1-\beta)\left\{Q\left(p\left(w_{I}^{a}\right)\right)+\left(w_{I}^{a}-c_{I}\right) Q^{\prime}\left(p\left(w_{I}^{a}\right)\right) p^{\prime}\left(w_{I}^{a}\right)\right\}}{\left(w_{I}^{a}-c_{I}\right) Q\left(p\left(w_{I}^{a}\right)\right)+F_{I}^{a}}=0, \\
& -\frac{\beta}{\Pi\left(w_{I}^{a}\right)-F_{I}^{a}}+\frac{(1-\beta)}{\left(w_{I}^{a}-c_{I}\right) Q\left(p\left(w_{I}^{a}\right)\right)+F_{I}^{a}}=0 .
\end{aligned}
$$

Substituting the second equation into the first one, we obtain

$$
-Q\left(p\left(w_{I}^{a}\right)\right)+Q\left(p\left(w_{I}^{a}\right)\right)+\left(w_{I}^{a}-c_{I}\right) Q^{\prime}\left(p\left(w_{I}^{a}\right)\right) p^{\prime}\left(w_{I}^{a}\right)=0
$$

Thus, we have $w_{I}^{a}=c_{I}$. Substituting it into the second equation, we obtain

$$
F_{I}^{a}=(1-\beta) \Pi\left(c_{I}\right)
$$

The resulting profits of $D$ and $U_{I}$, excluding the fixed compensation $x$, are given as

$$
\pi_{D}^{a}=\beta \Pi\left(c_{I}\right), \quad \pi_{U_{I}}^{a}=(1-\beta) \Pi\left(c_{I}\right)
$$

\section{2 $D$ rejects the exclusive offer}

Anticipating the outcome after the breakdown of the first negotiation, $D$ and $U_{E}$ negotiate their trading term. Note that for the breakdown of the first negotiation between $D$ and $U_{E}, D$ negotiates with $U_{I}$. Therefore, the bargaining outcome for the breakdown of the first negotiation coincides with the bargaining outcome in the previous subsection; namely, $D$ 's outside option under bargaining with $U_{E}$ is $\pi_{D}^{a}$. The bargaining problem between $D$ and $U_{E}$ is given as

$\left(w_{E}^{r}, F_{E}^{r}\right)=\arg \max _{w, F} \beta \log \left[(p(w)-w) Q(p(w))-F-\pi_{D}^{a}\right]+(1-\beta) \log \left[\left(w-c_{E}\right) Q(p(w))+F\right]$.

The maximization problem leads to the following two equations:

$$
\begin{aligned}
& -\frac{\beta Q\left(p\left(w_{E}^{r}\right)\right)}{\Pi\left(w_{E}^{r}\right)-F_{E}^{r}-\pi_{D}^{a}}+\frac{(1-\beta)\left\{Q\left(p\left(w_{E}^{r}\right)\right)+\left(w_{E}^{r}-c_{E}\right) Q^{\prime}\left(p\left(w_{E}^{r}\right)\right) p^{\prime}\left(w_{E}^{r}\right)\right\}}{\left(w_{E}^{r}-c_{E}\right) Q\left(p\left(w_{E}^{r}\right)\right)+F_{E}^{r}}=0, \\
& -\frac{\beta}{\Pi\left(w_{E}^{r}\right)-F_{E}^{r}-\pi_{D}^{a}}+\frac{(1-\beta)}{\left(w_{E}^{r}-c_{E}\right) Q\left(p\left(w_{E}^{r}\right)\right)+F_{E}^{r}}=0 .
\end{aligned}
$$


Substituting the second equation into the first one, we obtain

$$
-Q\left(p\left(w_{E}^{r}\right)\right)+Q\left(p\left(w_{E}^{r}\right)\right)+\left(w_{E}^{r}-c_{E}\right) Q^{\prime}\left(p\left(w_{E}^{r}\right)\right) p^{\prime}\left(w_{E}^{r}\right)=0
$$

Thus, we have $w_{E}^{r}=c_{E}$. Substituting it into the second equation, we obtain

$$
F_{E}^{r}=(1-\beta)\left(\Pi\left(c_{E}\right)-\pi_{D}^{a}\right)
$$

By using outcomes in (4), the resulting profits of firms are given as

$$
\pi_{D}^{r}=\beta \Pi\left(c_{E}\right)+(1-\beta) \beta \Pi\left(c_{I}\right), \quad \pi_{U_{I}}^{r}=0, \quad \pi_{U_{E}}^{r}=(1-\beta)\left(\Pi\left(c_{E}\right)-\beta \Pi\left(c_{I}\right)\right) .
$$

\subsection{Comparison}

We now consider the game in Stage 1. From the outcomes in (4) and (5), we derive the condition that $D$ accepts the exclusive offer by $U_{I}$. Substituting (4) and (5) into (3), we obtain

$$
\begin{aligned}
& (1-\beta) \Pi\left(c_{I}\right)+\beta \Pi\left(c_{I}\right) \geq\left(\beta \Pi\left(c_{E}\right)+(1-\beta) \beta \Pi\left(c_{I}\right)\right)+0, \\
\Rightarrow \quad & (1-\beta(1-\beta)) \Pi\left(c_{I}\right) \geq \beta \Pi\left(c_{E}\right) .
\end{aligned}
$$

From this condition, we obtain the following proposition:

Proposition 1 Suppose that upstream suppliers adopt two-part tariffs and that industry profits are allocated by bilateral Nash bargaining between D and upstream suppliers. $U_{I}$ can deter socially efficient entry as a unique equilibrium outcome if and only if

$$
\Pi\left(c_{E}\right) / \Pi\left(c_{I}\right) \leq \frac{1-\beta(1-\beta)}{\beta} \equiv \Gamma(\beta) .
$$

Note that for all $\beta \in(0,1)$, we have $\Gamma(\beta)>1, \Gamma^{\prime}(\beta)<0$, and $\Gamma^{\prime \prime}(\beta)>0$ and that $\Gamma(\beta) \rightarrow \infty$ as $\beta \rightarrow 0$ and $\Gamma(\beta) \rightarrow 1$ as $\beta \rightarrow 1$ (See Figure 1 ).

[Figure 1 about here] 
To understand our result, we compare sequential Nash bargaining characterized here with Nash bargaining with random proposers in Fumagalli et al. (2012). Regardless of bargaining types, the joint profits between $U_{I}$ and $D$ become $\Pi\left(c_{I}\right)$ when $D$ accepts the exclusive offer.

The crucial difference arises when $D$ rejects the exclusive offer. Under the case of random proposers, $U_{I}$ and $U_{E}$ become homogeneous Bertrand competitors with probability $1-\beta$, while $D$ makes the price offer with probability $\beta$. More importantly, when suppliers compete, $U_{I}$ offers its best term $\left(c_{I}, 0\right)$. As a result, Nash bargaining with random proposers induces $D$ to earn $\beta \Pi\left(c_{E}\right)+(1-\beta) \Pi\left(c_{I}\right)$, which is strictly larger than $\Pi\left(c_{I}\right)$. Therefore, exclusion never occurs in the absence of investments.

Sequential bargaining here, however, allows $U_{I}$ to offer $\left(c_{I},(1-\beta) \Pi\left(c_{I}\right)\right)$ off the equilibrium path. Hence, the competition between suppliers is less intense than under homogeneous Bertrand competition. This prevents $D$ from earning higher profits for the case of entry and thus there is room of exclusion outcomes; exclusion occurs even in the absence of investments. ${ }^{7}$ In addition, as $D$ 's bargaining power is weak, it earns lower profits; namely, the possibility of exclusion is higher when $D$ has limited bargaining power.

Our result provides an important policy implication for antitrust agencies; the possibility of anticompetitive exclusive dealing depends highly on the bargaining process when a downstream buyer negotiates with upstream suppliers. More concretely, anticompetitive exclusive dealing occurs if the buyer needs to negotiate with suppliers sequentially. Such exclusion is more likely to be observed in the case where the buyer faces some time constraints, which reduce its bargaining power, and limitations of negotiation opportunity.

\footnotetext{
${ }^{7}$ We can extend the analysis here to the case in which $N$ entrants exist and show the possibility of exclusion exists for the finite number of upstream suppliers. The proof of this result can be available upon request.
} 


\section{References}

Abito, J.M., and Wright, J., 2008. Exclusive Dealing with Imperfect Downstream Competition. International Journal of Industrial Organization 26(1), 227-246.

Aghadadashli, H., Dertwinkel-Kalt, M., and Wey, C., 2016. The Nash Bargaining Solution in Vertical Relations with Linear Input Prices. Economics Letters 145, 291-294.

Aghion, P., and Bolton, P., 1987. Contracts as a Barrier to Entry. American Economic Review 77(3), 388-401.

Bork, R.H., 1978. The Antitrust Paradox: A Policy at War with Itself. New York: Basic Books.

Fumagalli, C., Motta, M., and Rønde, T., 2012. Exclusive Dealing: Investment Promotion May Facilitate Inefficient Foreclosure. Journal of Industrial Economics 60(4), 599-608.

Kitamura, H., Matsushima, N., and Sato, M., 2016a. How Does Downstream Firms' Efficiency Affect Exclusive Supply Agreements? mimeo.

http://ssrn.com/abstract $=2306922$

Kitamura, H., Matsushima, N., and Sato, M., 2016b. Exclusive Contracts with Complementary Input. mimeo.

http://ssrn.com/abstract $=2547416$

Motta, M., 2004. Competition Policy. Theory and Practice. Cambridge: Cambridge University Press.

Posner, R.A., 1976. Antitrust Law: An Economic Perspective. Chicago: University of Chicago Press. 
Rasmusen, E.B., Ramseyer, J.M., and Wiley Jr., J.S., 1991. Naked Exclusion. American Economic Review 81(5), 1137-1145.

Rey, P., and Tirole, J., 2007. A Primer on Foreclosure. Handbook of Industrial Organization, Volume 3 Ch. 33, edited by M. Armstrong and R.H. Porter, 2145-2220, Amsterdam: North Holland.

Rey, P., and Vergé, T., 2008. Economics of Vertical Restraints. Handbook of Antitrust Economics Ch. 9, edited by P. Buccirossi, 353-390, Boston: MIT Press.

Segal, I.R., and Whinston, M.D., 2000. Naked Exclusion: Comment. American Economic Review 90(1), 296-309.

Simpson, J., and Wickelgren, A.L., 2007. Naked Exclusion, Efficient Breach, and Downstream Competition. American Economic Review 97(4), 1305-1320.

Whinston, M.D., 2006. Lectures on Antitrust Economics. Cambridge: MIT Press. 


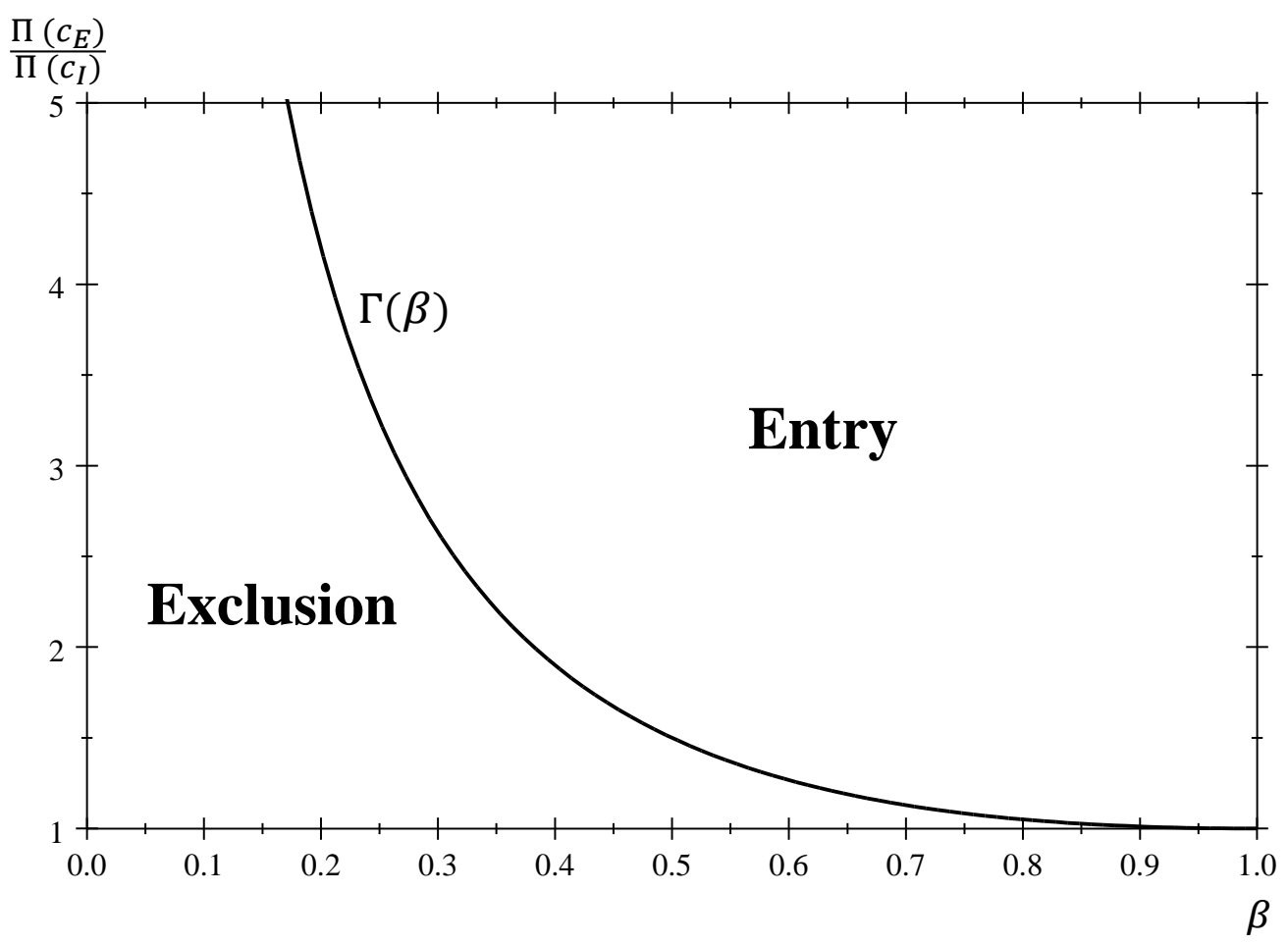

Figure 1: Results of Proposition 1 